\title{
Health Status and Health Facility Utilization of Community-Dwelling Elderly Living Alone in the Philippines: A Nationwide Cross-Sectional Study
}

\author{
TJ Robinson Moncatar, Keiko Nakamura* ${ }^{\mathbb{D}}$, Mosiur Rahman, Kaoruko Seino \\ Department of Global Health Entrepreneurship, Division of Public Health, Graduate School of Tokyo Medical and Dental \\ University, Tokyo, 113-8519, Japan \\ Email: ^nakamura.ith@tmd.ac.jp
}

How to cite this paper: Moncatar, T.R. Nakamura, K., Rahman, M. and Seino, K. (2019) Health Status and Health Facility Utilization of Community-Dwelling Elderly Living Alone in the Philippines: A Nationwide Cross-Sectional Study. Health, 11, 1554-1572.

https://doi.org/10.4236/health.2019.1111117

Received: October 27, 2019

Accepted: November 26, 2019

Published: November 29, 2019

Copyright () 2019 by author(s) and Scientific Research Publishing Inc. This work is licensed under the Creative Commons Attribution International License (CC BY 4.0)

http://creativecommons.org/licenses/by/4.0/

\begin{abstract}
Background: Increase of elderly people living alone has been a concern even in the Philippines where filial piety is widely practiced with the support of large number of young people. Objectives of this study were to examine the relationships between living alone with self-reported illness among community elderly and living alone with health facility utilization among sick community elderly in the Philippines. Methods: Data of 5577 elderly (aged $\geq 60$ years) from the 2013 Philippines National Demographic and Health Survey were retrieved. Variables on living arrangements, self-reported illness, frequency of health facility visits, and admission to a health facility were used for analysis. Results: Among the elderly included in the analysis, 5.0\% of them were living alone. Percentage of living alone was larger among rural elderly (6.0\%) compared with urban elderly (3.6\%); and among poor elderly $(9.0 \%)$ compared with rich elderly (2.8\%). Results of adjusted multivariate logistic regression analysis showed that the elderly living alone were more likely to report suffering from common colds (AOR 2.12; 95\% CI 1.57 - 2.86) or non-communicable diseases (AOR 2.18; 95\% CI 1.55 - 3.06), regardless of their socioeconomic status or insurance coverage. Among those who reported illness, the elderly living alone were more likely to visit a health facility with non-communicable disease (AOR 1.95; 95\% CI 1.22 - 3.14), after adjustment of other variables. Although elderly living alone who reported illness were likely to be admitted in a health facility, statistically significant association was not observed. Conclusion: Elderly living alone are more likely to report self-reported illness and use health facilities when they recognize their illness.
\end{abstract}

\section{Keywords}

Aging, Living Alone, Health Status, Health Facility Utilization, Philippines 


\section{Introduction}

Elderly population has been increasing continually at a rapid pace around the world. The 10-member countries of the Association of Southeast Asian Nations (ASEAN) are not an exception and projected that all will have an aged society by 2050 [1] including the Philippines [2], despite currently regarded as a predominant young society [3].

In particular, the elderly age group (aged 60 years and over) is associated with increased risk of illness development demanding greater specific health and social care requirements as compared with other age groups, wherein the current health care system needs to be adapted [4]. Increasing health and social care needs are eventual as health care utilization due to negative self-reported health status and multiple chronic communicable or non-communicable conditions were associated among older adults as observed in countries with similar context as the Philippines [5] [6].

The Philippines has a strong egalitarian familial bond [7]. Most elder Filipinos are co-residing with their adult children and unceasingly exchange inter-generational support with one another and given respect, power, and influence towards key decisions in the households [8]. However, the rapidly growing aging population is also confounded by the changing family structure in the Philippines, which has an impact on the well-being of the elderly [9]. Nuclearization of families is happening as average household size continuously decreases [7]. These demographic, socio-economic, and cultural transformations affect the family and household characteristics, and have led to an increasing number of elderly living alone [10] [11]. Notably, studies showed that the elderly living alone were of low socio-economic strata, isolated, lonely, have poorer lifestyle practices, decreased physical capacity and psychological well-being resulting in lower self-health rating, and quality of life [12] [13] [14].

Living arrangement has been important in the discourse of population aging as it provides information on the level of relationship and exchange of support an older household member receives and provides [15]. In the Philippines, co-residence with their adult children has been the norm and beneficial among older persons as they are assumed to receive better economic, physical, emotional, and psychological assistance and support [16] [17]. Hence, living arrangement of the elderly is an important predictor of their health status and health facility utilization [18]. However, an elderly living alone is viewed as an undesirable state and a potential health risk [14], which is a serious societal concern [19]. Due to social isolation and lack of social support, living alone has profound effect on the health status of an older person [20] and consequently on their use of health services [21]. Many studies have shown that an elderly living alone was at a higher risk of becoming ill, having difficulty with instrumental activities of daily living, worsening mobility, and suffering from depression [22] [23]. Furthermore, evidences from developed countries indicated that those living alone or having weak social relationships showed higher likelihood of health facility utilization [24] [25] [26]. 
Remarkably, majority of evidences focused on characteristics and relationship of living alone among elderly were commonly from developed countries or nations with strong patrilineal kinship system [27] [28] [29], wherein implications might be different from developing countries or those with endowed bilateral kinship system such as the Philippines. Furthermore, current epidemiological studies concerning interactive effects of older adult's social relationships, health status, and health care utilization are uncommon [30]. Evidences on aging from the Philippines largely focused on the perceptions of older adults, quality of life and older adults in the workforce [3]. Moreover, most of the descriptive and epidemiologic studies centralized on health outcomes were regarding self-rated health, functional independence, psychological well-being, and health facility use particularly among older persons in general [7] [31] [32]. Thus, epidemiologic studies to understand the effects and existence of association between elderly living arrangements, particularly living alone, on reported illness and consequently health facility utilization are needed. This is in line of the notion that household structure is a vital predictor of the overall well-being of an elderly. Therefore, studies on living arrangements should examine its impact on the lives of older persons [33], particularly recognizing its influence on their health status and health facility utilization due to illness. Further, future researches on health services for the elderly population should highlight the effects of social ties and support given that existing information is limited [34].

Amidst the unique family and social characteristics of the Philippines, there is now a growing proportion of elderly who live alone, and this is expected to increase further in the future, owing to several demographic factors. Therefore, given the anticipated growth of the elderly population which would demand diverse health and social care support systems, it is deemed necessary to determine the association of living alone among the elderly with their health status and health facility utilization. This vital information would largely assist policy and decision makers, program implementers, as well as health and social care workers in crafting and delivering worthwhile policies, programs, strategies, interventions, and care models which are tailor-fitted to specifically address the needs and idiosyncrasies of older persons in solitary living. Moreover, families are notified of potential repercussions of older family members living alone, particularly its influence on their self-reported illness and use of health facilities when they recognize illness.

In this study, we aimed to further this important area of inquiry by 1) examining the relationship between living alone and self-reported illness among community-dwelling elderly, and 2) determining the association between living alone on the utilization of health facilities among sick community-dwelling elderly in the Philippines.

\section{Methods}

\subsection{Data Sources}

This study utilized data from the 2013 Philippine National Demographic and 
Health Survey (PNDHS), which was conducted by the Philippine Statistics Authority (PSA) through technical support of MEASURE DHS program of ICF International. The datasets for the survey are available upon request at http://dhsprogram.com/data/available-datasets.cfm.

\subsection{Study Design, Sampling Size and Sampling Technique}

The 2013 PNDHS is a nationwide representative household-based survey. It is a stratified two-stage cluster sampling design using the 2010 Census of Population and Housing as a frame to ensure representativeness of the population. The first stage involved a systematic selection of 800 sample enumeration areas distributed by stratum. In the second stage, 20 sample-housing units were randomly selected from each of the sample enumeration areas. A total of 14804 households were successfully surveyed composed of 71893 individuals, yielding a response rate of 99.4 percent. In this study, information from 5577 elderly aged 60 years and over was included.

\subsection{Data Collection}

This survey utilized three questionnaires and data collected from the Household Questionnaire were used in this study, which identified socio-demographic and household characteristics, health insurance coverage, and information on health care utilization of each household member. Questionnaire development was based on a series of consultative meetings conducted within various agencies involved. The questionnaires were translated from English into six major languages of the Philippines and pilot tested to ensure reliability. Full survey details are available elsewhere [35].

\subsection{Measures}

\subsubsection{Outcome Variable}

Three outcome variables were measured in this study: 1) self-reported illness; 2) health facility visit; and 3) health facility admission due to illness. In this survey, self-reported illness was determined through measurement of the prevalence of common illnesses which severely affects the older population [36] [37]. Respondents were asked if they had common colds in the last 30 days. They were also questioned to report whether they had diabetes mellitus, cancer (all forms), or hypertension in the last 30 days. Those with any one or more of these conditions were grouped as having non-communicable diseases. Further, they were interviewed if they visited a health facility for advice or treatment in the last 30 days and if they had been admitted at a hospital/clinic during the last 12 months due to common colds or non-communicable diseases. All outcome variables were dichotomized as "yes" or "no".

\subsubsection{Exposure Variable}

Living arrangement of the elderly was the main exposure variable in this study. This was classified whether they were living alone, living with only one member, 
or living with two or more than household members. Living alone was defined as a person residing alone in a household independent from other adults or children.

\subsubsection{Other Covariate Variables}

Several socio-economic and demographic variables theoretically and empirically linked with health status and health facility utilization among the elderly were included [38] [39]. Age of the elderly was categorized as $60-69$ years, $70-79$ years, and 80 years or over. Gender was classified as male versus female. Place of residence was grouped as urban versus rural, based on the urban-rural classification of villages in the Philippines. Educational attainment was based on the country's formal education system classified as no education or pre-school, primary or elementary, secondary or high school, or higher level of education (college and post-graduate degrees). Wealth index was used as a proxy indicator for economic status and classified into poor, middle, or rich tertile. This was calculated based on household assets and housing characteristics. Scores were assigned based on the number and kinds of consumer goods that they owned, such as cars, bicycles and appliances, and the housing characteristics, such as availability of drinking water, toilet facilities, and flooring materials. These scores were derived using principal component analysis. Possession of health insurance was grouped as having no versus having health insurance such as government or private provided.

\subsection{Statistical Analysis}

We calculated the descriptive statistics for our sample's socio-economic and demographic characteristics including self-reported prevalence of common colds and non-communicable diseases, and health facility visit and admission due to illness by living arrangement. Chi-square test $\left(\chi^{2}\right)$ was used to assess the significance of differences in proportions. Multivariate logistic regression analysis was performed to examine the associations of the outcome variables, exposure variable, and other covariates. This was followed by a logistic regression computation with adjustments to determine association of outcome variables with the exposure variable after adjustments for socio-economic and demographic covariates. In all the analyses, the level of significance was set at $P<0.05$, two-sided. Multi-collinearity of the variables was checked by examining the variance inflation factors (VIFs), which was $<2.0$. The odds ratios (ORs) were estimated to assess the strength of the associations and the $95 \%$ confidence intervals (CIs) for significance testing. All covariates were entered simultaneously into the regression models. All estimates were weighted to correct for non-response and disproportionate sampling. Analysis was performed using SPSS version 23.0 (SPSS Inc; Chicago, IL, USA).

\subsection{Ethical Considerations}

The present study used a publicly available online dataset, wherein all identifier 
information was excluded. Therefore, no approval for ethical clearance was required for the current analysis. Moreover, the respondent's consent for participation in the survey was obtained, after he/she was explained the purpose of the survey and assured that all the information provided would be kept confidential, that participation was voluntary, and that he/she can refuse to answer any questions or discontinue the interview at any point.

\section{Results}

\subsection{Elderly Characteristics Classified by Living Arrangement}

Table 1 shows the distribution of living arrangements according to socio-economic and demographic factors, self-reported illness due to common colds or non-communicable diseases, and health facility visit and admission due to these illnesses among the elderly. Out of 5577 subjects included in this study, 281 (5.0\%) were living alone.

Table 1. Descriptive statistics according to living arrangements of elderly: 2013 Philippine National Demographic and Health Survey $(\mathrm{n}=5577)$.

\begin{tabular}{|c|c|c|c|c|c|}
\hline \multirow[t]{2}{*}{ Characteristics } & \multirow[t]{2}{*}{ Total, $\mathrm{n}$} & $\begin{array}{l}\text { Living with } \\
2+\text { members } \\
\text { (\%) }\end{array}$ & $\begin{array}{l}\text { Living with } \\
\text { only } 1 \text { member } \\
\text { (\%) }\end{array}$ & $\begin{array}{l}\text { Living alone } \\
\text { (\%) }\end{array}$ & \multirow[t]{2}{*}{$P$-value } \\
\hline & & $(\mathrm{n}=4350)$ & $(\mathrm{n}=946)$ & $(\mathrm{n}=281)$ & \\
\hline \multicolumn{6}{|l|}{ Age $(y r)$} \\
\hline $60-69$ & 3365 & 80.9 & 15.2 & 3.9 & \multirow{3}{*}{$<0.001$} \\
\hline $70-79$ & 1585 & 73.2 & 20.4 & 6.4 & \\
\hline $80+$ & 627 & 74.1 & 18.4 & 7.5 & \\
\hline \multicolumn{6}{|l|}{ Gender } \\
\hline Male & 2429 & 78.9 & 16.0 & 5.0 & \multirow{2}{*}{0.217} \\
\hline Female & 3148 & 77.3 & 17.8 & 4.9 & \\
\hline \multicolumn{6}{|l|}{ Place of Residence } \\
\hline Urban & 2157 & 81.2 & 15.2 & 3.6 & \multirow{2}{*}{$<0.001$} \\
\hline Rural & 3420 & 75.5 & 18.5 & 6.0 & \\
\hline \multicolumn{6}{|l|}{ Highest Educational Level } \\
\hline No Education, Preschool & 371 & 79.3 & 15.6 & 5.1 & \multirow{5}{*}{$<0.05$} \\
\hline Primary & 2935 & 76.4 & 17.8 & 5.8 & \\
\hline Secondary & 1238 & 80.6 & 15.5 & 3.9 & \\
\hline Higher & 1020 & 78.7 & 17.4 & 3.9 & \\
\hline Missing & 13 & & & & \\
\hline \multicolumn{6}{|l|}{ Economic Status } \\
\hline Poor & 2039 & 71.0 & 20.1 & 9.0 & \multirow{3}{*}{$<0.05$} \\
\hline Middle & 1121 & 78.1 & 18.5 & 3.4 & \\
\hline Rich & 2417 & 83.0 & 14.3 & 2.8 & \\
\hline
\end{tabular}




\section{Continued}

\begin{tabular}{|c|c|c|c|c|c|}
\hline \multicolumn{6}{|c|}{ Presence of Health Insurance } \\
\hline No & 2090 & 75.2 & 18.1 & 6.7 & \multirow{2}{*}{$<0.001$} \\
\hline Yes & 3486 & 79.7 & 16.4 & 3.9 & \\
\hline Missing & 1 & & & & \\
\hline \multicolumn{6}{|c|}{ Self-reported Common Colds } \\
\hline No & 4823 & 79.9 & 15.8 & 4.3 & \multirow{2}{*}{$<0.001$} \\
\hline Yes & 752 & 65.5 & 25.3 & 9.2 & \\
\hline Missing & 2 & & & & \\
\hline \multicolumn{6}{|c|}{ Self-reported NCDs ${ }^{\text {ab }}$} \\
\hline No & 4940 & 79.2 & 16.1 & 4.7 & \multirow{2}{*}{$<0.001$} \\
\hline Yes & 635 & 69.1 & 23.8 & 7.1 & \\
\hline Missing & 2 & & & & \\
\hline \multicolumn{6}{|c|}{$\begin{array}{l}\text { Health facility visit } \\
\text { due to Common Colds }\end{array}$} \\
\hline No & 5320 & 78.6 & 16.5 & 4.8 & \multirow{2}{*}{$<0.001$} \\
\hline Yes & 256 & 64.6 & 27.6 & 7.7 & \\
\hline Missing & 1 & & & & \\
\hline \multicolumn{6}{|c|}{ Health facility visit due to $\mathrm{NCDs}^{\mathrm{ab}}$} \\
\hline No & 5277 & 78.5 & 16.6 & 4.8 & \multirow{2}{*}{$<0.001$} \\
\hline Yes & 299 & 68.9 & 23.9 & 7.2 & \\
\hline Missing & 1 & & & & \\
\hline \multicolumn{6}{|c|}{$\begin{array}{l}\text { Health facility admission } \\
\text { due to Common Colds }\end{array}$} \\
\hline No & 5510 & 78.1 & 17.0 & 4.9 & \multirow{2}{*}{0.398} \\
\hline Yes & 67 & 72.1 & 19.7 & 8.2 & \\
\hline \multicolumn{6}{|c|}{$\begin{array}{c}\text { Health facility } \\
\text { admission due to NCDsac }\end{array}$} \\
\hline No & 5434 & 78.1 & 17.0 & 4.9 & \multirow{2}{*}{0.536} \\
\hline Yes & 143 & 78.0 & 17.0 & 6.3 & \\
\hline
\end{tabular}

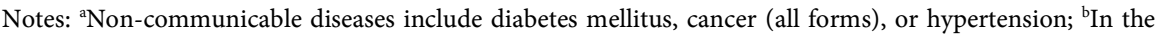
last 30 days; ' In the last 12 months.

Living alone was statistically more prevalent among those aged 80 years or over (7.5\%) versus younger elderly group, rural $(6.0 \%)$ versus dwelling in urban areas, poor $(9.0 \%)$ versus rich economic status, and without (6.7\%) versus having government or private health insurance. The prevalence of self-reported illness among elderly living alone in the last 30 days particularly due to common colds was at $9.2 \%$, while due to non-communicable diseases was at $7.1 \%$. Out of those elderly living alone who reported having an illness, $7.7 \%$ of those with common colds and $7.2 \%$ of those with non-communicable diseases visited a health facility for advice or treatment in the last 30 days. Although not statisti- 
cally significant, the proportion of admission to a health facility in the last 12 months among elderly living alone with common colds $(8.2 \%)$ or non-communicable diseases $(6.3 \%)$ were higher compared with elderly living in bigger household size.

\subsection{Relationship between Living Arrangement and Self-Reported Illness of Elderly}

Table 2 shows the results of the multivariate logistic regression analysis on the

Table 2. Odds ratios between living arrangement and self-reported illness of elderly: 2013 Philippine National Demographic and Health Survey $(\mathrm{n}=5577)$.

\begin{tabular}{|c|c|c|c|c|}
\hline \multirow{3}{*}{ Characteristics } & \multicolumn{4}{|c|}{ Self-Reported Illness in the Last 30 Days } \\
\hline & \multicolumn{2}{|c|}{ Have Common Colds [ORs and 95\% CIs] } & \multicolumn{2}{|c|}{ Have a NCD ${ }^{a}$ [ORs and 95\% CIs] } \\
\hline & Unadjusted & Adjusted $^{\mathrm{b}}$ & Unadjusted & Adjusted $^{\mathrm{b}}$ \\
\hline \multicolumn{5}{|l|}{ Living Arrangement } \\
\hline Living with $2+$ members & 1.00 & 1.00 & 1.00 & 1.00 \\
\hline Living with only 1 Member & $1.95(1.62-2.35)^{* *}$ & $1.80(1.49-2.18)^{\star *}$ & $1.70(1.39-2.06)^{\star *}$ & $1.78(1.46-2.18)^{\star *}$ \\
\hline Living Alone & $2.61(1.95-3.49)^{\star *}$ & $2.12(1.57-2.86)^{\star *}$ & $1.75(1.26-2.43)^{*}$ & $2.18(1.55-3.06)^{\star *}$ \\
\hline \multicolumn{5}{|c|}{ Socio-economic and Demographic Factors } \\
\hline \multicolumn{5}{|l|}{ Age $(y r)$} \\
\hline $60-69$ & & 1.00 & & 1.00 \\
\hline $70-79$ & & $1.25(1.04-1.49)^{\star}$ & & $1.50(1.25-1.80)^{\star \star}$ \\
\hline $80+$ & & $1.37(1.06-1.76)^{*}$ & & $1.47(1.12-1.91)^{*}$ \\
\hline \multicolumn{5}{|l|}{ Gender } \\
\hline Male & & 1.00 & & 1.00 \\
\hline Female & & $0.93(0.79-1.10)$ & & $1.40(1.18-1.66)^{\star *}$ \\
\hline \multicolumn{5}{|l|}{ Place of Residence } \\
\hline Urban & & 1.00 & & 1.00 \\
\hline Rural & & $1.28(1.07-1.53)^{*}$ & & $1.36(1.14-1.63)^{*}$ \\
\hline \multicolumn{5}{|l|}{ Highest Educational Level } \\
\hline No Education, Preschool & & 1.00 & & 1.00 \\
\hline Primary & & $0.88(0.64-1.22)$ & & $1.29(0.79-2.10)$ \\
\hline Secondary & & $0.76(0.52-1.09)$ & & $1.49(0.89-2.49)$ \\
\hline Higher & & $0.64(0.42-0.96)^{*}$ & & $1.53(0.90-2.59)$ \\
\hline \multicolumn{5}{|l|}{ Economic Status } \\
\hline Poor & & 1.00 & & 1.00 \\
\hline Middle & & $0.75(0.60-0.93)^{*}$ & & $1.94(1.49-2.52)^{\star *}$ \\
\hline Rich & & $0.54(0.43-0.67)^{\star *}$ & & $2.50(1.96-3.19)^{\star *}$ \\
\hline \multicolumn{5}{|l|}{ Presence of Health Insurance } \\
\hline No & & 1.00 & & 1.00 \\
\hline Yes & & $1.22(1.03-1.44)^{*}$ & & $1.42(1.18-1.71)^{* *}$ \\
\hline
\end{tabular}

Notes: Significance level: ${ }^{* *} P<0.001 ;{ }^{\star} P<0.05$; OR, odds ratio; CI, confidence interval; a Non-communicable diseases include diabetes mellitus, cancer (all forms), or hypertension; ${ }^{\mathrm{b}}$ Adjusted for age, gender, place of residence, highest educational level, economic status, and presence of health insurance. 
relationship between living arrangement and self-reported illness among the elderly. Elderly living alone were 2.6 times (OR 2.61; 95\% CI 1.95 - 3.49) more likely to report suffering from common colds and 1.8 times (OR 1.75; 95\% CI 1.26 - 2.43) more likely to report suffering from non-communicable diseases in the last 30 days. After adjustments for covariates, elderly living alone were still twice more likely to report suffering from common colds (AOR 2.12, 95\% CI 1.57 - 2.86) or non-communicable diseases (AOR 2.18; 95\% CI 1.55 - 3.06) in the last 30 days as compared to elderly living with two or more than household members.

Furthermore, in the adjusted models, we found out that elderly aged 80 years or over, residing in rural areas, and health insurance coverage were positively associated with reporting common colds in the last 30 days. Additionally, alongside these factors, elderly female and belonging to rich bands of wealth have greater likelihood to report suffering from non-communicable diseases in the last 30 days.

\subsection{Association between Living Arrangement and Health Facility Utilization among Elderly Who Reported Illness}

Table 3 shows the association between living arrangements and health facility utilization among elderly who reported illness. In both the unadjusted and adjusted models, elderly living alone were 1.7 times (OR 1.67; 95\% CI 1.05 - 2.65) and twice (AOR 1.95; 95\% CI 1.22 - 3.14) more likely to visit a health facility for advice or treatment due to non-communicable diseases in the last 30 days. On the other hand, elderly living with only one member were twice (OR 2.05; 95\% CI 1.53 - 2.75) and 1.9 times (AOR 1.90; 95\% CI 1.41 - 2.56) more likely to visit a health facility for advice or treatment due to common colds in the last 30 days.

Moreover, we have identified in the adjusted models that an elderly aged 70 79 and having health insurance were positively associated with outpatient health facility use for advice or treatment due to common colds in the last 30 days. Furthermore, aside from these factors, an elderly residing in rural area and belonging to rich economic status were independently associated with higher odds of visiting a health facility due to non-communicable diseases in the last 30 days.

In terms of utilization of inpatient health facilities, both the unadjusted and adjusted models showed that an elderly living alone with common colds were twice (OR 1.93; 95\% CI 0.78 - 4.78) (AOR 1.91; 95\% CI 0.75 - 4.85) more likely, while those with non-communicable diseases were 1.4 times (OR 1.37; 95\% CI $0.69-2.71$ ) and 1.6 times (AOR 1.56; 95\% CI 0.77 - 3.13) more likely to be admitted in a health facility in the last 12 months. However, we observed that these differences were not significant $(p>0.05)$.

In addition, we have identified in the adjusted models that the elderly aged 80 years or over and having health insurance were more likely to be admitted to a health facility due to common colds in the last 12 months. Also, apart from these factors, an elderly belonging to middle bands of wealth were independently 


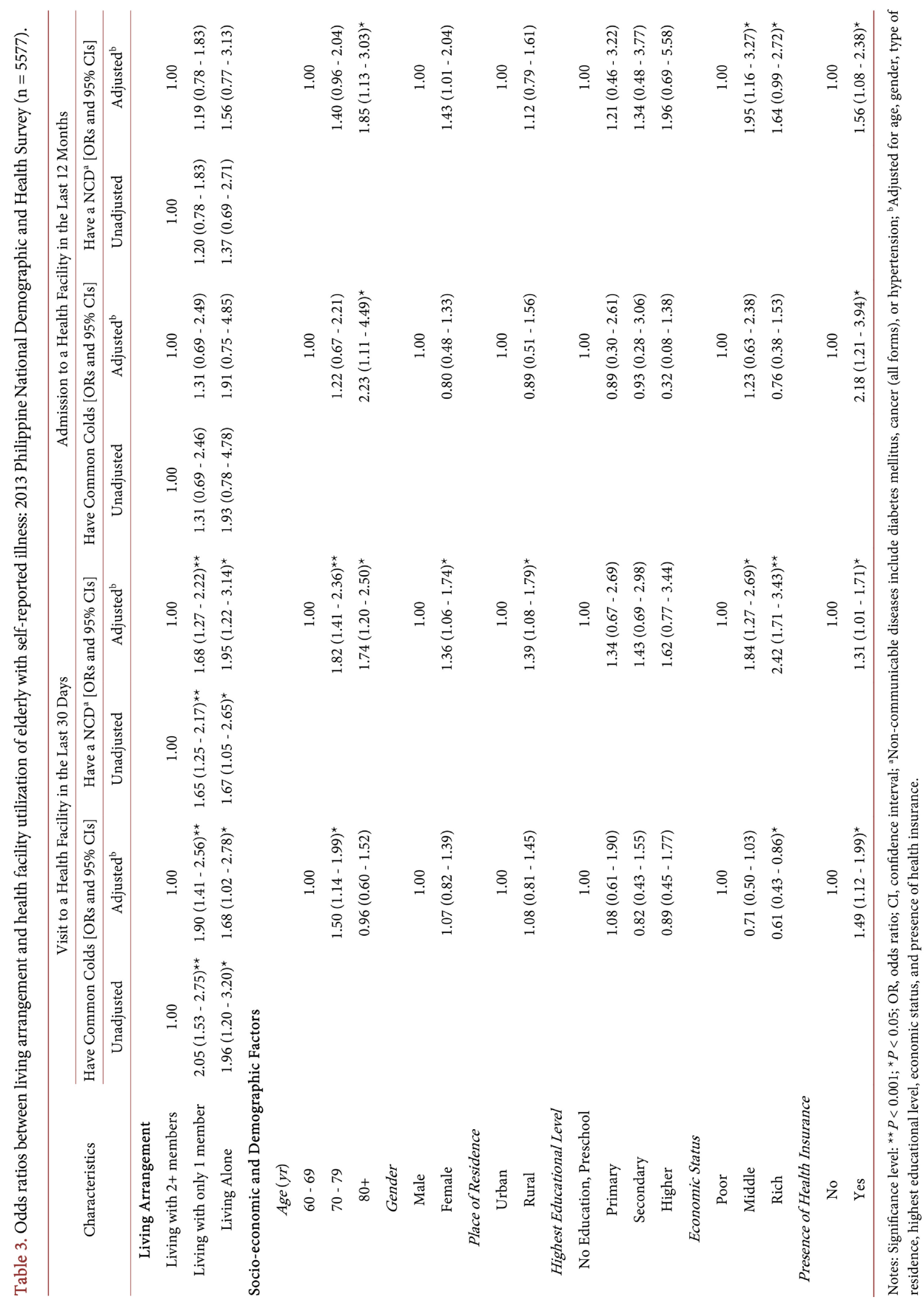


associated with higher odds of health facility admission due to noncommunicable diseases in the last 12 months.

\section{Discussion}

\subsection{Elderly Characteristics Classified by Living Arrangement}

The results of this survey indicated that although majority among elderly are co-residing in bigger or multi-generational households, elderly living alone in the Philippines is an issue necessitating reinforcement. The steadily changing household structure and demographics are likely attributed to stronger sense of autonomy and privacy, non-availability of kin, and in and out-migration of household members in search of economic improvement [8]. This is alarming as the results of this survey also highlighted that elderly who are living alone were prevalent among the most disadvantaged strata of the Philippine society. They are largely belonging to poor economic status, residing in rural areas, aged 80 years or above, and not covered by any government nor private health insurance. This finding was consistent with information derived from Demographic Health Surveys conducted in developing countries [10] and three countries in Southeast Asia [11] sharing similar socio-demographic characteristics as the Philippines.

Furthermore, higher prevalence of self-reported illness due to common colds and non-communicable diseases including health facility visit among elderly living alone with illness were observed. These findings were similar with a study from the United Kingdom which identified that community-dwelling elderly were more afflicted with common colds and went to medical practitioners for treatment and consultation [37]. In low- and middle-income countries, diabetes mellitus, cancers, and cardiovascular diseases including hypertension induces further health care demands among the elderly [36]. This situation among the elderly is further aggravated by the limited health care resources in the Philippines. Filipino elderly living alone require additional attention and assistance from different stakeholders due to undesirable characteristics and condition.

\subsection{Relationship between Living Arrangement and Self-Reported Illness of Elderly}

This study identified that elderly living alone are of greater odds to report suffering from an illness, regardless of socio-economic and demographic factors. Recently, it was identified that older adults living with more household members have the poorest health and less likely to report excellent health [40]. However, the results of the present study were similar with evidences from India, wherein family ties are also close-knit like the Philippines, which showed that elderly living alone were independently associated with higher likelihood of illness [19] [22]. This result conferred the influence of living alone on report of illness among older adults. Elderly living alone are at higher health risk due to absence of strong social relationships within the household leading to negative health 
gains. The lack of social support or social isolation affects elderly's immune, metabolic, and cardiovascular systems, particularly in those who have higher susceptibility with morbidity and mortality [41]. In a study conducted in Japan, existence of family support network plays a role in reducing the likelihood of poorer health status, as larger family structure enhances health awareness through easier access of information [42]. Living in a multi-generational household ensures strong social support and has an impact on the health outcomes, particularly in the prevention and management of illnesses [18]. This finding also highlighted the emotional and physical benefits of a bigger household structure offering closer family ties during times of stress. Elderly who are living alone have less access with social connections resulting in varying degrees of feelings of loneliness [43], leading to higher likelihood of illness development.

In addition, the current study underscored other specific socio-economic and demographic factors significantly associated with higher likelihood of reporting common colds and non-communicable diseases among the elderly, which were similarly reported in other studies elsewhere [44]-[48].

\subsection{Association between Living Arrangement and Health Facility Utilization among Elderly Who Reported Illness}

Another important finding of this study is that elderly living alone will visit a health facility when they experience illness, particularly if due to non-communicable diseases. This result is in contrast from a previous systematic review revealing that elderly who have social support were more likely to visit a physician than those without any or less social support [34]. However, the finding of the present study was consistent with studies in the United States of America, which identified that elderly living alone were more likely to visit an out-patient unit and emergency department for advice or treatment [24] [25]. An elderly experiencing any form of sickness will opt to live with family members rather than be alone in order to better cope with serious illnesses and receive instrumental social support, informal care giving assistance, and use available resources at home from their household members [40]. A strong and consistent social support keeps the elderly from seeking formal health services, as multiple household members perform significant caring roles that are beneficial to the well-being of the elderly [3]. In addition, an individual experiencing lack of household support during health catastrophe is more likely to visit a health facility not just for medical reasons, but also to satisfy their necessity for interaction and interpersonal simulation to fulfill their social support needs, aside from addressing their health concerns [49]. Higher frequency of health facility visits among elderly living alone can also be attributed to their functional ability. Better functional status among elderly living alone is associated with greater capability of accessing health and social care services independently as there has no other human support to address their needs [50]. Evidence from China has shown that an elderly with functional difficulties opt to cohabitate and co-reside with family members to receive support, rather than utilize health facilities [51]. Therefore, 
this result suggests that an elderly living alone is an important predictor of outpatient visit when they have illness.

Interestingly, elderly living with one household member showed greater odds of outpatient health visit due to common colds. This finding was consistent with a study conducted in Ireland which reported that an elderly with smaller domestic support were more likely to visit a health emergency unit for treatment due to illness [52]. This is likely attributed to high communicable disease attack rate within households [53] having easier disease transmission from an already sick household member to a vulnerable elderly in the household. Elderly persons are commonly afflicted with community-acquired infection that would require prompt medical attention [54]. Thus, significant daily contact with someone ill would increase the risk of infection [55]. This would necessitate immediate health facility visit for formal care support as the primary provider of informal care support, who is a source of positive health gains for an elderly in a multigenerational household, is also ailing.

Although elderly living alone showed the highest likelihood of health facility admission due to illness, we found no significant association. This finding was conferred with that of a longitudinal cohort study, which concluded that there was no significant association between living alone and the likelihood of hospitalization among the elderly [56]. Also, a study from the United States of America observed loneliness among older adults, which could be attributed to lack of social support, was not significantly associated with hospitalization [49]. This finding may suggest that it is likely that higher number of hospital admissions among the elderly living alone had serious illness or complications, requiring immediate medical attention. Further studies should be conducted in order to understand and conclude this outcome.

Moreover, this study highlighted other factors such as age, gender, place of residence, economic status, and presence of health insurance independently associated with outpatient and in-patient health facility use due to common colds and noncommunicable diseases among the elderly also observed in previous studies conducted [57] [58].

\subsection{Strengths and Limitations of the Study}

This study was a representative, randomly selected population-based sample with high response rate, ensured good statistical power, and reliable outcome results. Potential confounding factors were available and utilized in the analysis with small proportion of missing information or none to some variables. Interviewers who conducted the 2013 PNDHS were trained extensively for standardized administration of the interview process. This study distinctively examined the relationship between living arrangement, health status, and health facility utilization, which is usually not the case in epidemiologic studies focusing on associations with elderly social relationships. Relationship between living arrangement and self-reported illness, as well as frequency of health facility utilization among those with illness was uniquely investigated. Most studies focused 
only on either health status, including depression or functional ability, or health facility use, such as physician visits or hospitalization.

We must note some caveats to the findings of the present study. First, because this was a cross-sectional study, no causal relationships can be inferred. Future studies with more complex designs are necessary to verify and conclude causality. Second, misclassification bias might have occurred given that outcome variables, particularly health status measured were self-reported information. Collection of objective data is necessary to eliminate potential reporting errors or recall bias that would undoubtedly capture the relationships among variables. Third, proximity of children or relatives' residence among elderly living alone and their access with social networks outside the family, such as friends, neighbors, or community involvement, were not included in the survey. This information might influence significance of the findings of the study. Fourth, among those living with only one household member, it was not specified in the survey if the elderly are co-residing with a spouse, child, grandchild, other relatives, or with someone unrelated. Adding and clearly specifying this category would further enrich and allow a clearer interpretation of the findings.

\section{Conclusion}

In conclusion, based on a large, nationally representative sample, the elderly living alone in the Philippines are socio-economically and demographically disadvantaged. In a society where filial piety is strongly promoted, the elderly living alone have greater odds of reporting to suffer from an illness and utilize health facilities when they experience illness as compared among elderly living with larger number of household members. Not all elderly can reside with bigger households and receive the positive benefits of such arrangements due to several circumstances. Thus, the identified effects of living alone on the health status and health facility utilization among community-dwelling elderly will likely remain due to the changing household structure in the Philippines. These findings warrant the need to develop policies and strategies to address the health and social needs of elderly living alone. Future longitudinal studies are needed to further investigate the influence between living alone on health status and health facility utilization among the elderly population. Also, an in-depth exploration through qualitative methods could provide further interpretation of the findings.

\section{Acknowledgements}

We are grateful to ICF International, Rockville, Maryland, USA, through Measure DHS program for giving us permission to access the 2013 Philippine National Demographic and Health Survey 2013. In addition, we would like to acknowledge all individuals and institutions involved in the implementation of the 2013 Philippine National Demographic Health Survey.

\section{Funding Source}

This research was supported by the World Health Organization Centre for 
Health Development (WHO Kobe Centre-WKC: K18017).

\section{Conflicts of Interest}

The authors declare that there is no conflict of interest.

\section{References}

[1] United Nations Economic and Social Commission for Asia and the Pacific (2017) Ageing in the Asian and Pacific Region: An Overview. Economic and Social Commission for Asia and the Pacific, Bangkok, Thailand.

https://www.unescap.org/sites/default/files/SDD\%20Ageing\%20Fact\%20Sheet $\% 20$ O verview.pdf

[2] Philippine Statistics Authority. (2014) A 142 Million Philippine Population by 2045? https://psa.gov.ph/content/142-million-philippine-population-2045

[3] Badana, A.N.S. and Andel, R. (2018) Aging in the Philippines. Gerontologist, 58, 212-218. https://doi.org/10.1093/geront/gnx203

[4] Shrivastava, S.R.B.L., Shrivastava, P.S. and Ramasamy, J. (2013) Health-Care of Elderly: Determinants, Needs and Services. International Journal of Preventive Medicine, 4, 1224-1225.

[5] Ameh, S., Gómez-Olivé, F.X., Kahn, K., Tollman, S.M. and Klipstein-Grobusch, K. (2014) Predictors of Health Care Use by Adults 50 Years and over in a Rural South African Setting. Global Health Action, 7, 1-11. https://doi.org/10.3402/gha.v7.24771

[6] Fernández-Olano, C., Hidalgo, J.D.L.T., Cerdá-Díaz, R., Requena-Gallego, M., Sánchez-Castaño, C., Urbistondo-Cascales, L. and Otero-Puime, A. (2006) Factors Associated with Health Care Utilization by the Elderly in a Public Health Care System. Health Policy, 75, 131-139. https://doi.org/10.1016/j.healthpol.2005.02.005

[7] Chen, F., Bao, L., Shattuck, R.M., Borja, J.B. and Gultiano, S. (2017) Implications of Changes in Family Structure and Composition for the Psychological Well-Being of Filipino Women in Middle and Later Years. Research on Aging, 39, 275-299. https://doi.org/10.1177/0164027515611181

[8] Domingo, L.J. and Asis, M.M.B. (1995) Living Arrangements and the Flow of Support between Generations in the Philippines. Journal of Cross-Cultural Gerontology, 10, 21-51. https://doi.org/10.1007/BF00972030

[9] Raymo, J.M., Kikuzawa, S., Liang, J. and Kobayashi, E. (2008) Family Structure and Well-Being at Older Ages in Japan. Journal of Population Research, 25, 379-400. https://doi.org/10.1007/BF03033896

[10] Bongaarts, J. and Zimmer, Z. (2002) Living Arrangements of Older Adults in the Developing World: An Analysis of Demographic and Health Survey Household Surveys. Journal of Gerontology: Social Sciences, 57, 145-157.

https://doi.org/10.1093/geronb/57.3.S145

[11] Teerawichitchainan, B., Knodel, J. and Pothisiri, W. (2015). What Does Living Alone Really Mean for Older Persons? A Comparative Study of Myanmar, Vietnam, and Thailand. Demographic Research, 32, 1329-1360. https://doi.org/10.4054/DemRes.2015.32.48

[12] Chen, Y., Hicks, A. and While, A.E. (2014) Quality of Life and Related Factors: A Questionnaire Survey of Older People Living Alone in Mainland China. Quality of Life Research, 23, 1593-1602. https://doi.org/10.1007/s11136-013-0587-2

[13] Hawton, A., Green, C., Dickens, A.P., Richards, S.H., Taylor, R.S., Edwards, R., Campbell, J.L., et al. (2011) The Impact of Social Isolation on the Health Status and 
Health-Related Quality of Life of Older People. Quality of Life Research, 20, 57-67. https://doi.org/10.1007/s11136-010-9717-2

[14] Kharicha, K., Iliffe, S., Harari, D., Swift, C., Gillmann, G. and Stuck, A.E. (2007) Health Risk Appraisal in Older People 1: Are Older People Living Alone an at-Risk Group? The British Journal of General Practice: The Journal of the Royal College of General Practitioners, 57, 271-276.

[15] Wandera, S.O., Ddumba, I., Akinyemi, J.O., Adedini, S.A. and Odimegwu, C. (2017) Living Alone among Older Persons in Uganda: Prevalence and Associated Factors. Ageing International, 42, 429-446. https://doi.org/10.1007/s12126-017-9305-7

[16] Abejo, S. D. (2004) Living Arrangements of the Elderly in the Philippines. 9th National Convention on Statistics (NCS), Mandaluyong City, Philippines, 4-5 October 2004.

[17] Knodel, J. and Ofstedal, M.B. (2002) Patterns and determinants of living arrangements. In: Hermalin, A.I., Eds., The Well-Being of the Elderly in Asia: A Four-Country Comparative Study, University of Michigan Press, Ann Arbor, MI, 143-184.

[18] Hays, J.C. (2002) Living Arrangements and Health Status in Later Life: A Review of Recent Literature. Public Health Nursing, 19, 136-151. https://doi.org/10.1046/j.1525-1446.2002.00209.x

[19] Agrawal, S. (2012) Effect of Living Arrangement on the Health Status of Elderly in India: Findings from a National Cross Sectional Survey. Asian Population Studies, 8, 37-41. https://doi.org/10.1080/17441730.2012.646842

[20] Henning-Smith, C. (2017) Quality of Life and Psychological Distress among Older Adults: The Role of Living Arrangements. Journal of Applied Gerontology, 35, 39-61. https://doi.org/10.1177/0733464814530805

[21] Schafer, M.H. (2013) Discussion Networks, Physician Visits, and Non-Conventional Medicine: Probing the Relational Correlates of Health Care Utilization. Social Science and Medicine, 87, 176-184. https://doi.org/10.1016/j.socscimed.2013.03.031

[22] Samanta, T., Chen, F. and Vanneman, R. (2014) Living Arrangements and Health of Older Adults in India. Journals of Gerontology Series B: Psychological Sciences and Social Sciences, 70, 937-947. https://doi.org/10.1093/geronb/gbu164

[23] Sun, X., Lucas, H., Meng, Q. and Zhang, Y. (2011) Associations between Living Arrangements and Health-Related Quality of Life of Urban Elderly People: A Study from CHINA. Quality of Life Research, 20, 359-369.

https://doi.org/10.1007/s11136-010-9752-Z

[24] Guzman, J.S., Sohn, L. and Harada, N.D. (2004) Living Alone and Outpatient Care Use by Older Veterans. Journal of the American Geriatrics Society, 52, 617-622. https://doi.org/10.1111/j.1532-5415.2004.52172.x

[25] Hastings, S.N., George, L.K., Fillenbaum, G.G., Park, R.S., Burchett, B.M. and Schmader, K.E. (2008) Does Lack of Social Support Lead to More ED Visits for Older Adults? American Journal of Emergency Medicine, 26, 454-461. https://doi.org/10.1016/j.ajem.2007.07.005

[26] Walter-Ginzburg, A., Chetrit, A., Medina, C., Blumstein, T., Gindin, J. and Modan, B. (2001) Physician Visits, Emergency Room Utilization, and Overnight Hospitalization in the Old-Old in Israel: The Cross-Sectional and Longitudinal Aging Study (CALAS). Journal of the American Geriatrics Society, 49, 549-556. https://doi.org/10.1046/j.1532-5415.2001.49112.x

[27] Iliffe, S., Tai, S.S., Haines, A., Gallivan, S., Goldenberg, E., Booroff, A. and Morgan, P. (1992) Are Elderly People Living Alone an at Risk Group? British Medical Journal, 305, 1001-1004. https://doi.org/10.1136/bmj.305.6860.1001 
[28] Jennifer Yeh, S.C. and Lo, S.K. (2004) Living Alone, Social Support, and Feeling Lonely among the Elderly. Social Behavior and Personality. An International Journal, 32, 129-138. https://doi.org/10.2224/sbp.2004.32.2.129

[29] Sun, W., Watanabe, M., Tanimoto, Y., Shibutani, T., Kono, R., Saito, M., Kono, K., et al. (2007) Factors Associated with Good Self-Rated Health of Non-Disabled Elderly Living Alone in Japan: A Cross-Sectional Study. BMC Public Health, 7, Article No. 297. https://doi.org/10.1186/1471-2458-7-297

[30] Valtorta, N.K., Moore, D.C., Barron, L., Stow, D. and Hanratty, B. (2018) Older Adults' Social Relationships and Health Care Utilization: A Systematic Review. American Journal of Public Health, 108, e1-e10. https://doi.org/10.2105/AJPH.2017.304256

[31] Cruz, G., Natividad, J., Gonzales, M. and Saito, Y. (2016) Aging in the Philippines: Findings from the 2007 Philippine Study on Aging. University of the Philippines Population Institute and Demographic Research and Development Foundation. Inc., Quezon City, Philippines. https://www.drdf.org.ph/

[32] Cruz, G.T., Saito, Y. and Natividad, J.N. (2007) Active Life Expectancy and Functional Health Transition among Filipino Older People. Canadian Studies in Population, 34, 29. https://doi.org/10.25336/P62K6R

[33] Velkoff, V.A. (2001) Living Arrangements and Well-Being of the Older Population: Future Research Directions. United Nations, Department of Economic and Social Affairs, New York. Population Division. https://pdfs.semanticscholar.org/adf0/f5101944ed6fa9f8f8fb05fc8c83c55b90ff.pdf

[34] Bremer, D., Inhestern, L. and von dem Knesebeck, O. (2017) Social Relationships and Physician Utilization among Older Adults-A Systematic Review. PLoS ONE, 12, e0185672. https://doi.org/10.1371/journal.pone.0185672

[35] Philippine Statistics Authority (PSA) [Philippines], ICF International (2014) Philippines National Demographic and Health Survey 2013. http://dhsprogram.com/pubs/pdf/FR294/FR294.pdf

[36] Boutayeb, A. and Boutayeb, S. (2005) The Burden of Non Communicable Diseases in Developing Countries. International Journal for Equity in Health, 4, 1-8. https://doi.org/10.1186/1475-9276-4-2

[37] Nicholson, K.G., Kent, J., Hammersley, V. and Cancio, E. (1996) Risk Factors for Lower Respiratory Complications of Rhinovirus Infections in Elderly People Living in the Community: Prospective Cohort Study. British Medical Journal, 313, 1119-1123. https://doi.org/10.1136/bmj.313.7065.1119

[38] Gong, C.H., Kendig, H. and He, X. (2016) Factors Predicting Health Services Use among Older People in China: An Analysis of the China Health and Retirement Longitudinal Study 2013. BMC Health Services Research, 16, 1-16.

https://doi.org/10.1186/s12913-016-1307-8

[39] Park, J.M. (2014) Health Status and Health Services Utilization in Elderly Koreans. International Journal for Equity in Health, 13, 1-7.

https://doi.org/10.1186/s12939-014-0073-7

[40] Weissman, J.D. and Russell, D. (2018) Relationships between Living Arrangements and Health Status among Older Adults in the United States, 2009-2014. Journal of Applied Gerontology, 37, 7-25. https://doi.org/10.1177/0733464816655439

[41] White, A.M., Philogene, G.S., Fine, L. and Sinha, S. (2009) Social Support and Self-Reported Health Status of Older Adults in the United States. American Journal of Public Health, 99, 1872-1878. https://doi.org/10.2105/AJPH.2008.146894

[42] Turagabeci, A.R., Nakamura, K., Kizuki, M. and Takano, T. (2007) Family Structure 
and Health, How Companionship Acts as a Buffer against Ill Health. Health and Quality of Life Outcomes, 5, 1-9. https://doi.org/10.1186/1477-7525-5-61

[43] Cornwell, E. and Waite, L. (2009) Social Disconnectedness, Perceived Isolation and Health among Older Adults. Journal of Health and Social Behavior, 50, 31-48. https://doi.org/10.1177/002214650905000103

[44] Nicholson, K.G., Kent, J., Hammersley, V. and Cancio, E. (1997) Acute Viral Infections of Upper Respiratory Tract in Elderly People Living in the Community: Comparative, Prospective, Population-Based Study of Disease Burden. British Medical Journal, 315, 1060-1064. https://doi.org/10.1136/bmj.315.7115.1060

[45] Jowett, M., Deolalikar, A. and Martinsson, P. (2004) Health Insurance and Treatment Seeking Behaviour: Evidence from a Low-Income Country. Health Economics, 13, 845-857. https://doi.org/10.1002/hec.862

[46] Ng, N., Stenlund, H., Bonita, R., Hakimi, M., Wall, S. and Weinehall, L. (2006) Preventable Risk Factors for Noncommunicable Diseases in Rural Indonesia: Prevalence Study Using WHO STEPS Approach. Bulletin of the World Health Organization, 84, 305-313. https://doi.org/10.2471/BLT.05.023721

[47] Mini, G.K. and Thankappan, K.R. (2017) Pattern, Correlates and Implications of Non-Communicable Disease Multimorbidity among Older Adults in Selected Indian States: A Cross-Sectional Study. BMJ Open, 7, e013529.

https://doi.org/10.1136/bmjopen-2016-013529

[48] Cano-Gutierrez, C., Reyes-Ortiz, C.A., Samper-Ternent, R., Gélvez-Rueda, J.S. and Borda, M.G. (2015) Prevalence and Factors Associated to Hypertension among Older Adults in Bogotá, Colombia. Journal of Aging and Health, 27, 1046-1065. https://doi.org/10.1177/0898264315573518

[49] Gerst-Emerson, K. and Jayawardhana, J. (2015) Loneliness as a Public Health Issue: The Impact of Loneliness on Health Care Utilization among Older Adults. American Journal of Public Health, 105, 1013-1019. https://doi.org/10.2105/AJPH.2014.302427

[50] Sarwari, A., Fredman, L., Langenberg, P. and Magaziner, J. (1998) Prospective Study on the Relation between Living Arrangement and Change in Functional Health Status of Elderly Women. American Journal of Epidemiology, 147, 370-378. https://doi.org/10.1093/oxfordjournals.aje.a009459

[51] Li., L, Zhang, J. and Liang, J. (2009) Health among the Oldest-Old in China: Which Living Arrangements Make a Difference? Social Science \& Medicine, 68, 220-227. https://doi.org/10.1016/j.socscimed.2008.10.013

[52] Naughton, C., Drennan, J., Treacy, P., Fealy, G., Kilkenny, M., Johnson, F. and Butler, M. (2010) The Role of Health and Non-Health-Related Factors in Repeat Emergency Department Visits in an Elderly Urban Population. Emergency Medicine Journal, 27, 683-687. https://doi.org/10.1136/emj.2009.077917

[53] Barker, J., Stevens, D. and Bloomfield, S.F. (2001) Spread and Prevention of Some Common Viral Infections in Community Facilities and Domestic Homes. Journal of Applied Microbiology, 91, 7-21. https://doi.org/10.1046/j.1365-2672.2001.01364.x

[54] Yoshikawa, T.T. and Marrie, T.J. (2001) Special Section: Aging and Infectious Diseases. Community-Acquired Pneumonia in the Elderly. Clinical Infectious Disease, 31, 1066-1078. https://doi.org/10.1086/318124

[55] Smieszek, T., Fiebig, L. and Scholz, R.W. (2009) Models of Epidemics: When Contact Repetition and Clustering Should Be Included. Theoretical Biology and Medical Modelling, 6, 1-15. https://doi.org/10.1186/1742-4682-6-11

[56] Ennis, S.K., Larson, E.B., Grothaus, L., Helfrich, C.D., Balch, S. and Phelan, E.A. 
(2014) Association of Living Alone and Hospitalization Among Community-Dwelling Elders With and Without Dementia. Journal of General Internal Medicine, 29, 1451-1459. https://doi.org/10.1007/s11606-014-2904-Z

[57] Madyaningrum, E., Chuang, Y. and Chuang, K. (2018) Factors Associated with the Use of Outpatient Services among the Elderly in Indonesia. BMC Health Services Research, 18, Article No. 707. https://doi.org/10.1186/s12913-018-3512-0

[58] Jiang, M., Yang, G., Fang, L., Wan, J., Yang, Y. and Wang, Y. (2018) Factors Associated with Healthcare Utilization among Community-Dwelling Elderly in Shanghai, China. PLoS ONE, 13, e0207646. https://doi.org/10.1371/journal.pone.0207646 